\title{
Energy Efficient Operation of Light Rail Transit (LRT) System for Kelana Jaya Line via Train Headway Time in Malaysia
}

\author{
A Adilah, C S Tan, C L Toh
}

\begin{abstract}
With the advancement of new technologies in the rail system, there is a possibility that the energy consumption in the rail system will increase if no efforts are taken to ensure sustainability in the Light Rail Transit (LRT). Therefore, efforts on reducing energy consumption in LRT through optimizing train operational with a good control strategy is crucial to achieve energy saving whilst ensuring efficient use of energy. Train operations such as unchanged dwell time, increase in the length of journey, increase number of trains and train weight are few factors that may increase the traction energy consumption of the LRT system. However, due to frequent changes in passengers commuting between stations, controlling energy consumption will be a challenge as energy consumption keeps fluctuating most of the time coupled with signal delays at intersection and unexpected problem occur along the line. One of the energy saving measures is to control the train headway time. In the context of this research, headway time is defined as the time interval of the tip of one train to the tip of the next one behind it. The regularity of the headway time can be improved by adjusting the dwell time or running time between stations for each train. This paper presents a potential of energy saving at various headway time with increase number of car-train scheduled. Based on the simulation analysis, it indicates that there is a possibility that energy consumption per day can be reduced by5.9\% with a reduction of $5 \%$ of the current headway time.
\end{abstract}

Keywords: Light Rail Transit, Kelana Jaya Line, Energy Efficient Operation.

\section{OVERVIEW OF TRAIN NETWORK IN ASEAN COUNTRY}

Generally, rail system helps to improve economics of a country apart from providing connectivity between cities and people. In ASEAN countries, the rail system helps to move massive people across one city to another on a daily basis. Nevertheless, the quality of the railroads and or the efficiency of the rail system plays an important role in ensuring low carbon mobility in the country. Figure 1 shows the ranking of the ASEAN countries in term of quality of rail roads where Myanmar was not included in [1]. The quality of railroads is defined as the condition of the tracks and equipment of transit system used. The ranking score is in the range of 1 to 7 , with the latter being the highest. Among the ASEAN countries depicted in Fig. 1, Singapore scored the highest at 5.9 followed by Malaysia at 5.0,
Indonesia at 4.2, Vietnam at 3.0, Thailand at 2.6, Philippines and Cambodia at 1.9 and 1.6 respectively. No data reported for Laos and Brunei. Other studies conducted by [1-2] shows that Singapore rail system is distinguished by its efficiency use of electric train which running on two different type of systems namely, Mass Rail Transit (MRT) as their primary system and Light Rail Transit (LRT) as secondary system to reach out to the nearest cities. Both rail systems have total rail tracks of $199.5 \mathrm{~km}$.

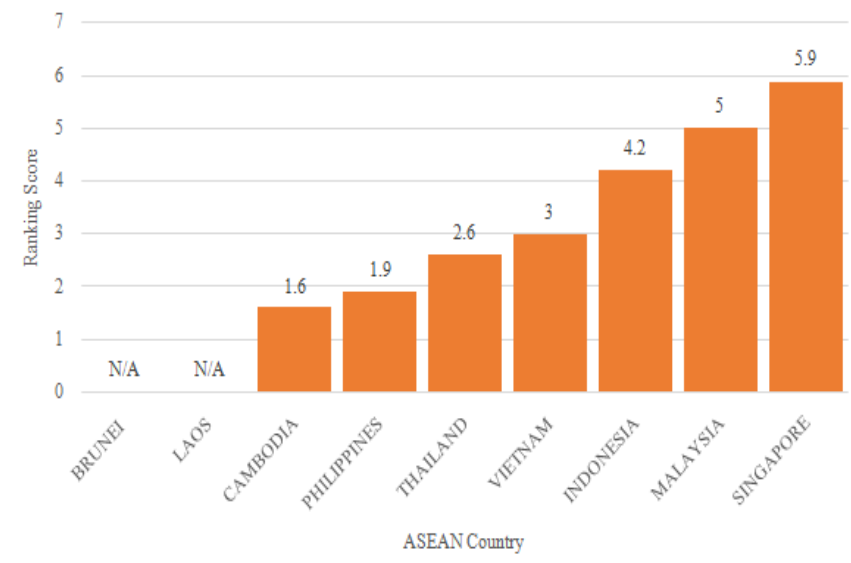

Fig. 1 Ranking of ASEAN country in quality of railroads

Similar to Singapore rail system, Malaysia started to run its first MRT back in December 2018. Prior to MRT, all electric rail systems in Malaysia are operating on LRT system, Monorail, Express Rail Line (ERL) and KTM Komuter. All the railway electrification systems are located and concentrated in the Greater Kuala Lumpur and Klang Valley. KTM is a commuter rail system in Malaysia which was introduced to provide mobility for the public especially in Kuala Lumpur and Klang Valley. The total length of the KTM rail is $456 \mathrm{~km}$, LRT Kelana Jaya Line is $46.4 \mathrm{~km}$, Mass Rail Transit (MRT) is $52.2 \mathrm{~km}$ and ERL is $57 \mathrm{~km} \mathrm{[3-}$ 6]. The Malaysia rail layout tracks are different from Singapore where Singapore are more extensive and peoplecentric, while Malaysia railway systems is spatial and yet fully people-centric. Other ASEAN countries such as Jakarta are moving forward to introduce more electric rail projects as part of the low carbon mobility initiative in the country. 


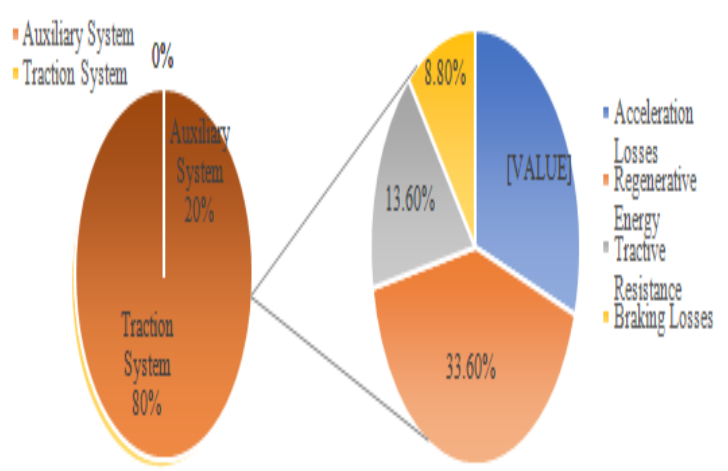

Fig. 2 Energy consumption distribution in rail transit system

Figure 2 illustrates that the train energy consumption can be divided into two parts which are the traction system and auxiliary systems reported in [7], the auxiliary systemconsumed $20 \%$ of the total train energy consumption. It is used to run the ventilation, air-conditioning and illumination equipment. The energy consumption is mainly influenced by the weather and climate conditions. The other $80 \%$ is consumed by the traction system. These energies are due to acceleration losses (24\%), regenerative energy (33.6\%), tractive resistance $(13.6 \%)$ and braking losses $(8.8 \%)$. Research in [8]also indicates that computational fluid dynamics can be used to find the behavior of passengers through simulation and this will help to design an efficient energy air conditioning system of subway stations.

However, giving attention to the aerodynamic design and the ambiance condition of a train to reduce the energy consumption are less effective. Therefore, focus on the train operations and time scheduling are more crucial in improving its energy efficiency. Many researchers had conducted various studies related to train journey time, dwell time and train operation speeds in order to save energy consumption[9-10]. Reducing headway time of a train had shown a positive effect on energy saving operation because it allows more services and more flexible scheduling. This is supported by study done in [11] where it indicates that regularity of the headway time can decrease the train delay time and average passengers waiting time subsequently saves energy usage in traction system.
Furthermore it also indicates that increasing number of passengers will affect the headway time schedule.

A recent research in [12] shows that having a reasonable adjustment of the dwell time can also improve the possibilities of traction and braking conditions to improve the utilization of regenerative energy where dwell time refers to time before the doors open, period of time during passenger exchange and the time prior to departure after the doors have closed. Generally, the dwell time for the doors to open and closed is fixed. Research in [13] reported that reducing headways time by $2 \%$ to $3 \%$ could reduce energy consumption by $5.7 \%$ based on station length. Nevertheless, it is undeniable hard to meet the traffic demand and operation with fixed headway and synchronization time in regard with low energy consumption.

There is also potential energy saving of $10-15 \%$ by modifying headway times by $20 \%$ as reported in [14]. In other words, by having an optimum head way time of train, it could contribute to a good usage of regenerative energy. Research carried out by [15-16] show that train with lighter weight has positive effect on its own energy saving operation. Research in [17-18] conduct the study on the operation of the train with headway variation on transit routes at various train speed. The study looks into the potential of line capacity allowable at different headway for different train speed. Only a few researchers are focusing on the train headway time on energy consumption of a train. In this paper, the impact of headway time between trains in LRT Kelana Jaya Line is presented and analyzed. This paper also looks into the potential energy consumption and saving for a LRT system operation with different headway time using Kelana Jaya Line LRT as a case study.

\section{METHODOLOGY}

Figure 3 shows the Kelana Jaya Line that consists of 37 stations with a total of $46.4 \mathrm{~km}$ track length, some of the stations are elevated and some are underground. The distant varies between stations as indicated in Fig.3. The speed limit for Kelana Jaya Line train is $80 \mathrm{~km} / \mathrm{h}$. Nevertheless, the train speed travelling between stations varies. To avoid complexity without loss of generality, this paper focuses on the train operation where train headway time is selected as one of the key factors affecting the energy consumption in LRT Kelana Jaya Line.

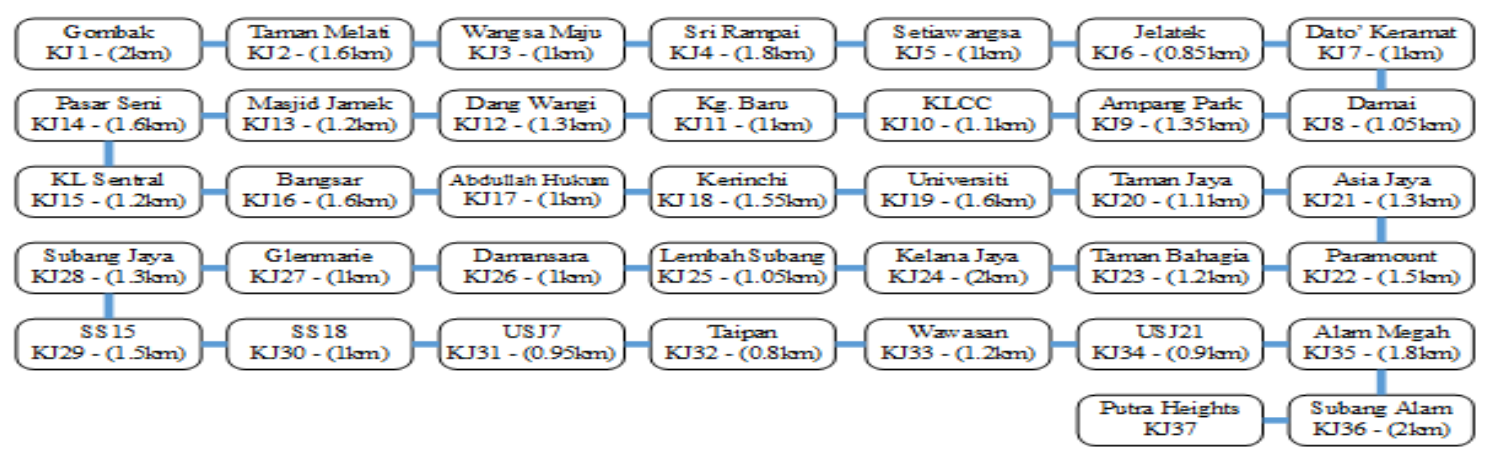

Fig. 3 LRT Kelana Jaya Line map route with distance within Stations

The headway time is calculated using Equation (1) below;

Headway Time $=\frac{\text { Journey Time }}{\text { No of Train per Time Slot }}$ 
The total energy consumption $E_{c}$ by the trains per day is calculated using Equation (2) below;

$$
E_{c}=\sum_{t=1}^{\text {Time Slot }} n \times P \times T_{t}
$$

Where, $n$ is the number of linear induction motor per car train travelling between $\mathrm{KJ} 1$ and $\mathrm{KJ} 37, P$ is the nominal power of the linear induction motor in watt, $T_{t}$ is the duration of the train travelling between $\mathrm{KJ} 1$ and $\mathrm{KJ} 37$ per time slot expressed in hour.
Table 1 shows the LRT Kelana Jaya Line parameters used to determine the headway and energy consumption. In order to determine the efficient operation of LRT via headway time, 6 scenarios analysis are performed as illustrated in Table 2. The scenarios analyses help to investigate each potential total energy consumption with the reduction of headway from $\pm 5 \%$ to $\pm 20 \%$ at $\pm 5 \%$ interval and also changes of type of trains scheduling per time slot.

Table. 1 Data parameters of LRT Kelana Jaya Line

\begin{tabular}{lc}
\hline \multicolumn{1}{c}{ Descriptions } & Units \\
\hline Route length from KJ1 to KJ37 & $46.4 \mathrm{~km}$ \\
Total journey time per trip & 84 minutes \\
$\begin{array}{l}\text { Number of Linear Induction Motor } \\
\text { per car }\end{array}$ & 2 \\
Number of stations & 37 \\
$\begin{array}{l}\text { Linear Induction Motor Nominal } \\
\text { Power, } P\end{array}$ & $155 \mathrm{~kW}$ \\
\hline
\end{tabular}

Table. 2 Scenarios Analysis for LRT Kelana Jaya Line

\begin{tabular}{|c|c|c|}
\hline Scenario & Headway & 2-Car \& 4-Car trains \\
\hline Scenario 1: Baseline & Existing Scheduling & Current Trains Scheduling \\
\hline Scenario 2 & $\begin{array}{l} \pm 5 \% \text { to } \pm 20 \% \text { at } \pm 5 \% \text { interval change from } \\
\text { its current headway }\end{array}$ & No change in Current Trains Scheduling \\
\hline Scenario 3 & same as above & $\begin{array}{l}25 \% \text { 2-car trains, } 75 \% 4 \text {-car trains per time } \\
\text { slot }\end{array}$ \\
\hline Scenario 4 & same as above & $\begin{array}{l}30 \% \text {-car trains, } 70 \% 4 \text {-car trains per time } \\
\text { slot }\end{array}$ \\
\hline Scenario 5 & same as above & $\begin{array}{l}40 \% 2 \text {-car trains, } 60 \% 4 \text {-car trains per time } \\
\text { slot }\end{array}$ \\
\hline Scenario 6 & same as above & $\begin{array}{l}50 \% \text { 2-car trains, } 50 \% 4 \text {-car trains per time } \\
\text { slot }\end{array}$ \\
\hline
\end{tabular}

\section{RESULTS AND DISCUSSIONS}

The current journey time, trains headway per time slot and the current trains scheduling are obtained from Rapid Rail
Control Center department. The speed train travelling along Kelana Jaya Line stations varies between $50 \mathrm{~km} / \mathrm{h}$ and $80 \mathrm{~km} / \mathrm{h}$.

Table. 3 Current trains' schedules and its headway time for a same journey time between KJ1 and KJ37

\begin{tabular}{|c|c|c|c|c|c|}
\hline \multirow[b]{2}{*}{ Time slot } & \multicolumn{4}{|c|}{ Current Trains Scheduling \& Headway Time } & \multirow{2}{*}{$\begin{array}{l}\text { Energy } \\
\text { Consumption, } \\
\mathrm{kWh}\end{array}$} \\
\hline & $\begin{array}{l}\text { 2-Car } \\
\text { Trips, } \mathrm{X}_{1}\end{array}$ & $\begin{array}{l}4 \text { Car } \\
\text { Trips, } Y_{1} \\
\end{array}$ & $\begin{array}{l}\text { No of train per time } \\
\text { slot, } A_{1}=X_{1}+Y_{1}\end{array}$ & $\begin{array}{l}\text { Average Headway } \\
\text { Time (Min) }\end{array}$ & \\
\hline 0600-0700 & 10 & 28 & 38 & 2.2 & 57,288 \\
\hline $\begin{array}{l}\text { 0700-0900 } \\
\text { (Peak Hour) }\end{array}$ & 13 & 49 & 62 & 1.4 & 96,348 \\
\hline 0900-1700 & 18 & 12 & 30 & 2.8 & 36,456 \\
\hline $\begin{array}{l}1700-1930 \\
\text { (Peak Hour) }\end{array}$ & 13 & 49 & 62 & 1.4 & 96,348 \\
\hline $1930-2200$ & 11 & 7 & 18 & 4.7 & 21,700 \\
\hline \multirow[t]{2}{*}{$2200-2400$} & 6 & 6 & 12 & 7.0 & 15,624 \\
\hline & & & \multicolumn{2}{|c|}{ Total Energy Consumption per day: } & 323,764 \\
\hline
\end{tabular}

Table 3 shows that the current trains scheduling per time slot and its headway time. Based on the current scheduling, the headway during peak hour for Kelana Jaya line is 1.4 minutes and the non-peak hour setting ranging from 2.2 


\section{Energy Efficient Operation of Light Rail Transit (LRT) System for Kelana Jaya Line via Train Headway Time in Malaysia}

minutes to 7 minutes. It is also observed that, during peak hours the total number of car-train are 62 cars and during non-peak hours the total car-train ranging from 12 to 38 cars. In other words, the average headway time of $2.2 \mathrm{~min}$ or 132 second leads to a capacity of 38 trains per hour for the time slot between $6 \mathrm{am}$ and $7 \mathrm{am}$. The system operates for 18 hours a day with a total of 222 trips per day.

Based on the same train journey time taken between $\mathrm{KJ} 1$ and $\mathrm{KJ} 37$, the total number of trains per time slot is calculated using Equation (1) and are tabulated in Table 4 between $\pm 5 \%$ and $\pm 20 \%$ at $\pm 5 \%$ from its current headway. Table 4 indicates, more trains can be put into services with a shorter headway time as compared to current schedules and headway time. Hence, with a shorter headway time the number of train per time slot can be increased subsequently energy consumption will increase and vice versa. Nevertheless, the total energy consumption by the trains depend on the number of 2-car or 4 car scheduled per time slot.

Table. 4 Total number of trains per time slot due to headway changes between $\pm 5 \%$ and $\pm 20 \%$

\begin{tabular}{cccccccccc}
\hline \multirow{2}{*}{ Time slot } & \multirow{2}{*}{ Baseline } & \multicolumn{3}{c}{ Headway (Increases) } & \multicolumn{3}{c}{ Headway (Decreases) } \\
\cline { 3 - 9 } & & $+5 \%$ & $+10 \%$ & $+15 \%$ & $+20 \%$ & $-5 \%$ & $-10 \%$ & $-15 \%$ & $-20 \%$ \\
\hline 0600-0700 & 38 & 36 & 35 & 33 & 32 & 40 & 42 & 45 & 48 \\
0700-0900 (Peak Hour) & 62 & 59 & 56 & 54 & 52 & 65 & 69 & 73 & 78 \\
0900-1700 & 30 & 29 & 27 & 26 & 25 & 32 & 33 & 35 & 38 \\
$1700-1930$ (Peak Hour) & 62 & 59 & 56 & 54 & $52-$ & 65 & 69 & 73 & 78 \\
$1930-2200$ & 18 & 17 & 16 & 16 & 15 & 19 & 20 & 21 & 23 \\
$2200-2400$ & 12 & 11 & 11 & 10 & 10 & 13 & 13 & 14 & 15 \\
\hline Total & 222 & 211 & 201 & 193 & 186 & 234 & 246 & 261 & 280 \\
\hline
\end{tabular}

Figure 4 shows the relationship between total energy consumption and the percentage headway changes based on the six scenarios in Table 2. These simulations indicate that the total energy consumption per day for all scenarios ranging between $241,304 \mathrm{kWh}$ and $426,188 \mathrm{kWh}$. Fig. 4 also indicates that the total energy consumptions are lower than the baseline (i.e., scenario 1) when the head way increases (i.e., lesser trains in service) and vice versa.

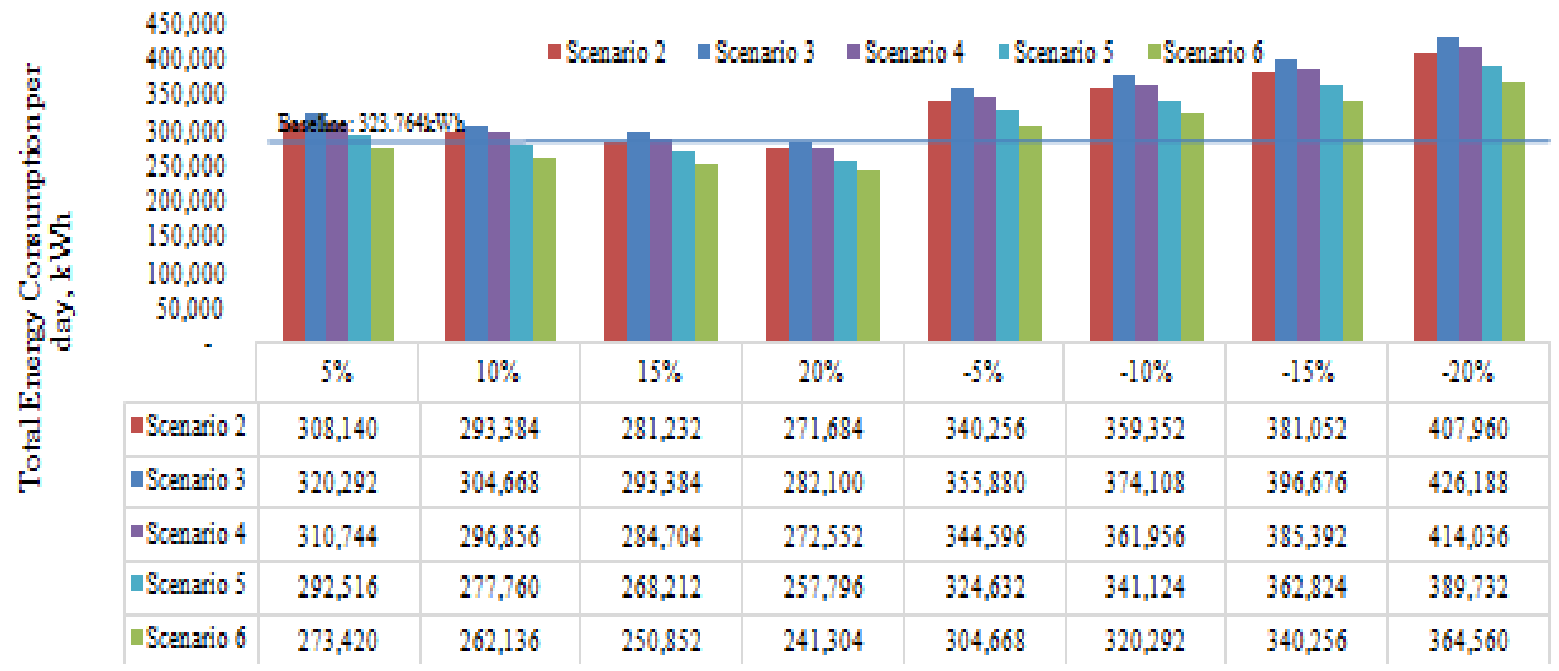

Fig. 4 Total energy consumption due to headway changes between $\pm 5 \%$ and $\pm 20 \%$

Table 5 tabulates the percentage of energy consumption savings due to headway changes between $\pm 5 \%$ and $\pm 20 \%$. These analysis indicate that, with a shorter headway time, more car trains can be scheduled hence energy consumption increases and otherwise (i.e., from scenario 2 to scenario 5). However, with efficient operation and train scheduling, energy consumption can be reduced with the decrease of headway as indicated in scenario 6 of Table 5 . The total energy consumption in scenario 6indicates that the energy consumption per day can be reduced by $5.9 \%$ with a reduction of $5 \%$ from its current headway time. Similarly, when the headway decrease by $10 \%$ the total energy consumption can be reduced by $1.1 \%$. 
Table. 5 Percentage of energy consumption savings due to headway changes between $\pm 5 \%$ and $\pm 20 \%$

\begin{tabular}{lllllllll}
\hline \multirow{2}{*}{ Scenarios } & \multicolumn{3}{c}{ Headway (Increases) } & \multicolumn{5}{c}{ Headway (Decreases) } \\
\cline { 2 - 8 } & $+5 \%$ & $+10 \%$ & $+15 \%$ & $+20 \%$ & $-5 \%$ & $-10 \%$ & $-15 \%$ & $-20 \%$ \\
\hline Scenario 2 & $-4.8 \%$ & $-9.4 \%$ & $-13.1 \%$ & $-16.1 \%$ & $5.1 \%$ & $11.0 \%$ & $17.7 \%$ & $26.0 \%$ \\
Scenario 3 & $-1.1 \%$ & $-5.9 \%$ & $-9.4 \%$ & $-12.9 \%$ & $9.9 \%$ & $15.5 \%$ & $22.5 \%$ & $31.6 \%$ \\
Scenario 4 & $-4.0 \%$ & $-8.3 \%$ & $-12.1 \%$ & $-15.8 \%$ & $6.4 \%$ & $11.8 \%$ & $19.0 \%$ & $27.9 \%$ \\
Scenario 5 & $-9.7 \%$ & $-14.2 \%$ & $-17.2 \%$ & $-20.4 \%$ & $0.3 \%$ & $5.4 \%$ & $12.1 \%$ & $20.4 \%$ \\
Scenario 6 & $-15.5 \%$ & $-19.0 \%$ & $-22.5 \%$ & $-25.5 \%$ & $-5.9 \%$ & $-1.1 \%$ & $5.1 \%$ & $12.6 \%$ \\
\hline
\end{tabular}

\section{CONCLUSIONS}

In this paper, six scenarios analysis are presented to illustrate the efficient operation of LRT Kelana Jaya via headway and trains scheduling. This study indicates, with a reduction of $5 \%$ of its current headway time, energy consumption can be further reduced by $5.9 \%$. In other words, there is potential of energy consumption reduction with the decrease of headway time and the type of car-train (i.e., 2car trains or 4-car trains) schedules. Nevertheless, details analysis need to be performed to determine further energy reduction potential with more practical train headway time and number of passengers travelled for LRT Kelana Jaya Line.

\section{ACKNOWLEDGMENTS}

The authors are grateful and appreciate Rapid Rail Sdn. Bhd for sharing few data's on LRT Kelana Jaya Line time scheduling and other related information for the study. This research work is supported and funded by Universiti Tenaga Nasional (Innovation and Research Management Centre, iRMC) internal grant. Any opinions, findings and conclusions expressed in this paper are from the authors and do not necessarily reflect the views of the Rapid Rail Sdn. Bhd, Ministry of Education, Universiti Tenaga Nasional or the Institute.

\section{REFERENCES}

1. "Which ASEAN Economy Has The Most Developed Infrastructure?" [Online]. Available: Https://Www.Rappler.Com/Business/187905Asean-Summit-2017-Philippines-Competitiveness. [Accessed: 28-Mar2019].

2. "ASEAN Metro/What Was The 1st Rapid Transit Electric Rail Line In The ASEAN?" [Online]. Available: Http://Livingasean.Com/Explore/Asean-Metro/. [Accessed: 28-Mar2019].

3. "KTM Komuter, Port Klang Line \&Amp; Seremban Line Klia2.Info." [Online]. Available: Http:/Www.Klia2.Info/Rail/KtmKomuter/. [Accessed: 28-Mar-2019].

4. "Kuala Lumpur Monorail - Railway Technology." [Online]. Available: Https://Www.Railway-

Technology.Com/Projects/Kualalumpurmonorail/. [Accessed: 28-Mar2019].

5. "Sungai Buloh - Serdang - Putrajaya (SSP Line) - MRT Corp." [Online]. Available: Https://Www.Mymrt.Com.My/Public/Sg-BulohSerdang-Putrajaya-Ssp-Line/. [Accessed: 28-Mar-2019].

6. "Kelana Jaya Line LRT, 46km Of Grade-Separated LRT Rail Tracks With 37 Stations - Klia2.Info." [Online]. Available: Http://Www.Klia2.Info/Rail/Rapidkl-Lrt/Kelana-Jaya-Line/. [Accessed: 28-Mar-2019].
7. X. Yang, X. Li, B. Ning, And T. Tang, "A Survey On Energy-Efficient Train Operation For Urban Rail Transit" IEEE Transactions On Intelligent Transportation Systems, Vol. 17, No. 1, pp. 2-13 (2016).

8. K. Fukuyo, "Application Of Computational Fluid Dynamics And Pedestrian-Behavior Simulations To The Design Of Task-Ambient AirConditioning Systems Of A Subway Station”, Energy, 2006, Vol. 31, No. 5, pp. 706-718 (2006).

9. P. G. Howlett, P. J. Pudney, And X. Vu, "Local Energy Minimization In Optimal Train Control" Automatica, Vol. 45, No. 11, pp.2692-2698 (2009).

10. R. Liu And I. M. Golovitcher, "Energy-Efficient Operation of Rail Vehicles", Transportation Reseach Part A: Policy and Practice, Vol. 37, No. 10, pp. 917-932 (2003).

11. B. Ning, J. Xun, S. Gao, And L. Zhang, "An Integrated Control Model For Headway Regulation And Energy Saving In Urban Rail Transit", IEEE Transactions on Intelligent Transportation Systems, Vol. 16, No. 3, pp. 1469-1478 (2015).

12. J. Feng, X. Li, H. Liu, X. Gao, And B. Mao, "Optimizing The EnergyEfficient Metro Train Timetable \& Control Strategy In Off-Peak Hours With Uncertain Passenger Demands" Energies, Vol. 10, No. 4, pp. 1-20 (2017).

13. D. Hasegawa, G. L. Nicholson, C. Roberts, And F. Schmid, "The Impact Of Different Maximum Speeds On Journey Times, Energy Use, Headway Times And The Number Of Trains Required For Phase One Of Britain's High Speed Two Line" WIT Transactions nn The Built Environment, Vol. 135, pp. 485-496 (2014).

14. T. Albrecht, "Reducing Power Peaks And Energy Consumption in Rail Transit Systems By Simultaneous Train Running Time Control”, WIT Transactions nn The Built Environment, Vol. 74, pp.885-894 (2004).

15. M. Kwak, S. Yun, Y. Lee, H. Kwon, K. Kim, And D. H. Lee, "Optimum Nose Shape Of A Front-Rear Symmetric Train For The Reduction Of The Total Aerodynamic Drag" Journal of Mechanical Science and Technolgoy, Vol. 27, No. 12, pp. 3733-3743 (2013).

16. H. Q. Tian, "Formation Mechanism Of Aerodynamic Drag Of HighSpeed Train And Some Reduction Measures" Journal of Central South University of Technology, Vol. 16, No.1, pp. 166-171 (2009).

17. Jacques Rabouel, Paula Robin and Andrew Boagey, "Operational Concept Study Technical Note: HS2 Capacity and Reliability", SYSTRA, (2011)

18. M. Abkowitz, A. Eiger, And I. Engelstein, "Optimal Control of Headway Variation on Transit Routes", Journal of Advanced Transportation, Vol. 20, No.1, pp.73-88 (1986).

19. Padmapriya, T., Saminadan, V. "QoE based carrier aggregation techniques in LTE-Advanced networks", Proceedings of the International Conference on Intelligent Sustainable Systems, ICISS 2017,2018 